\title{
Primary amenorrhea - a one year review
}

\begin{abstract}
Objective: Primary amenorrhea occurs in about $0.1-2 \%$ of reproductive age group women. The aim of this study was to evaluate the etiology and management of patients with primary amenorrhea in a tertiary referral centre.

Material and Methods: The study was performed using 13 complete medical records of women with primary amenorrhea who attended the Department of Obstetrics and Gynecology, Maxcure Suyosha Hospital, Hyderabad, India between May 2015 and May 2016. Out of the 13 cases, 8 had 46XX Mullerian agenesis (MRKH syndrome), 4 had 46XY Androgen Insensitivity Syndrome (AIS) and 1 had 45XO/46XY Turner mosaic syndrome. Neovagina formation was done in 8 cases, bilateral gonadectomy was done in 5 cases and bilateral salpingectomy in 3 cases by laparoscopic methods.

Results: Minimally invasive removal of gonads was accomplished with less morbidity to patients and without any complications. Histopathology of gonads revealed a sertoli cell pattern in 3 cases and gonadoblastoma in 2 cases. Successful application of surgical technique of neovagina creation using Interceed was achieved in patients with vaginal agenesis.

Conclusion: Management of primary amenorrhea is a multi-modal approach with the type of intervention based on the etiology. A thorough evaluation to identify the cause for amenorrhea and timely surgical intervention would produce a better cosmetic and functional result and address the psychosocial issues associated with this condition.
\end{abstract}

Keywords: Mullerian agenesis, Neovagina, Androgen insensitivity syndrome, Turner mosaic syndrome, Gonadectomy
Volume 6 Issue I - 2017

\author{
Manjula Anagani,' Prabha Agrawal, ${ }^{2}$ Radhika \\ B, ${ }^{3}$ Dola Sridevi, ${ }^{4}$ Mahitha Karee, ${ }^{4}$ Sireesha $E^{5}$ \\ 'Head of Department, Maxcure Suyosha Hospitals, India \\ ${ }^{2}$ Consultant obstetrician and gynaecologist, Maxcure Suyosha \\ Hospitals, India \\ ${ }^{3}$ Consultant obstetrician and gynaecologist, Maxcure Suyosha \\ Hospitals, India \\ ${ }^{4}$ DGO, Registrar at Maxcure Suyosha Hospitals, India \\ ${ }^{5}$ MS, Registrar at Maxcure Suyosha Hospitals, India
}

Correspondence: Manjula Anagani MD, FICOG, Head of Department, Chief gynae, obst and Laparoscopic Surgeon at Maxcure Suyosha Hospitals, Flat no. 208,Aparna Chandra Deep, Banjara Hills, Road no. 7, Hyderabad, India, Emailmanjuangani@yahoo.com

Received: September 0I, 2016 | Published: January 06, 2017

\section{Introduction}

Primary amenorrhea is the failure of menstruation to occur by the age of 16 years in the presence of normal growth and secondary sexual characteristics. If by age 13 menstruation has not occurred and the onset of puberty is absent, a workup for primary amenorrhea should start. It occurs in about $2 \%$ of reproductive age group. The most common causes are related to chromosomal abnormalities followed by endocrinological causes like hypothalamic hypogonadism and pituitary disease. The other causes include Mullerian abnormalities, $\mathrm{CAH}$, Poly Cystic Ovarian Syndrome (PCOS).

\section{Objective}

The objective of the current study was to study the etiology, clinical manifestation, diagnostic and treatment options in a series of thirteen cases of primary amenorrhea who presented to our out-patient clinics during the period between May 2015 and May 2016.

\section{Management}

A retrospective analysis of our case records revealed thirteen cases of primary amenorrhea between the age groups of 13 and 26 years. All of them presented with complaints of having not attained menarche. They entered puberty with normal or underdeveloped secondary sexual characteristics with normal, absent or short vaginal pouch. External genitalia were either normal or underdeveloped female or under masculinized with bilateral undescended testes with a previous history of inguinal herniorraphy.

The diagnostic work-up included taking a detailed history, examination, ultrasonography and MRI of pelvis. Karyotype mapping was done in all the patients and Hormonal assay included testing the levels of FSH, LH, TSH, Prolactin and Testosterone. The management was by psychological counseling to patient and family members in all cases, sex assignment and a combined medical and various surgical treatments depending on the etiology. The various surgical treatments included genitoplasty, gonadectomy and salpingectomy. The patients were given hormone replacement therapy (HRT), fertility counseling and follow up advice.

We present a detailed review of three variants of the 13 cases dealt with in a year
a. 46XY AIS,
b. 45XO/46XX TURNER Mosaic and
c. $46 X X$ Mullerian Agenesis

\section{Case I}

A 19 year-old phenotypic female with a height of $162 \mathrm{~cm}$ and a weight of $49 \mathrm{~kg}$ presented with primary amenorrhea. Physical examination showed normal development of breast (Tanner stage 2) with no pubic and axillary hairs, a soft swelling next to pubic bone in left groin, healthy normal external genitalia with blind vaginal pouch of $2 \mathrm{~cm}$. Her FSH was $7.5 \mathrm{IU}$ and total testosterone was $11.27 \mathrm{ng} / \mathrm{ml}$. MRI revealed a hypoplastic uterus with a $24 \times 12 \mathrm{~mm}$ right ovary and a small cystic focus measuring $13 \times 27 \mathrm{~mm}$ in the left groin adjacent to pubic bone suspected to be left ovarian tissue. The karyotype was 46XY. A working diagnosis of Androgen Insensitivity Syndrome (AIS) was made. Counselling about gender identity was done and in this case the patient wished to be raised as a female.

Informed consent was taken for Laparoscopic bilateral gonadectomy. At laparoscopy the uterus was not seen and right gonad 
was seen near deep inguinal ring (DIR) (Figure 1). Left gonad was not visualised near DIR (Figure 2). It was felt beyond superficial inguinal ring subcutaneously near pubic bone.DIR was closed with vicryl. A bilateral gonadectomy was done. Histopathology confirmed bilateral testicular tissue with sertoli cells only (Figure 3). She was advised a noevagina creation later.

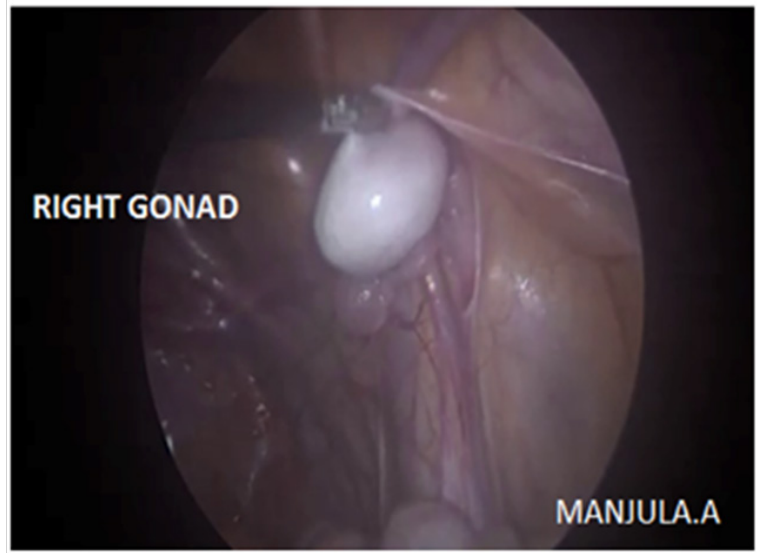

Figure I Right gonad near deep inguinal ring.

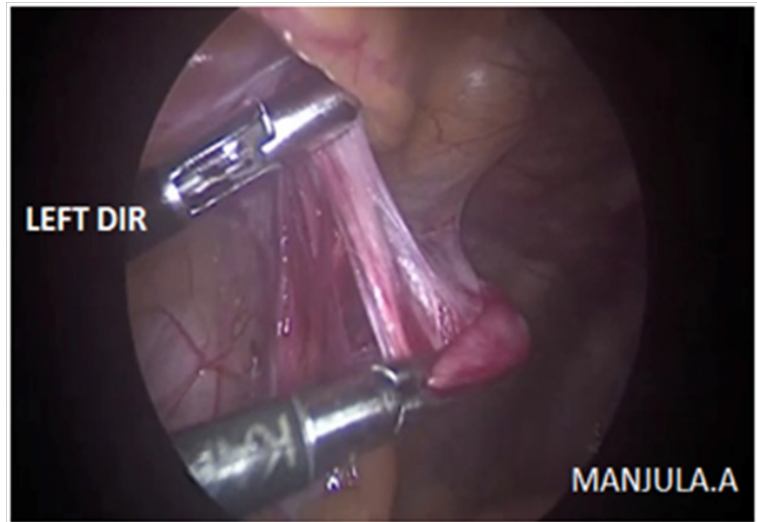

Figure 2 Left deep inguinal ring, gonad not found in inguinal canal.

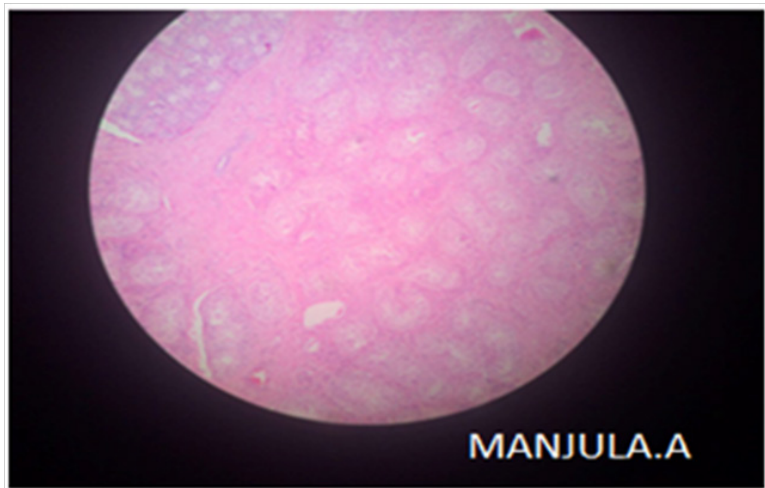

Figure 3 Seminiferous tubules with sertoli cells only.

\section{Case 2}

A 13 year old phenotypic female with a height of $150 \mathrm{~cm}$ and a weight of $45 \mathrm{~kg}$ presented with primary amenorrhea. Physical examination showed breast development Tanner stage 1 with no axillary and pubic hair, normal external genitalia and a fully formed vagina. Hormonal analysis showed FSH $-92.6 \mathrm{IU}$ and Serum estradiol-<5.0.MRI revealed uterus of size $4.5 \times 1.1 \times 2.7 \mathrm{~cm}$, Right ovary $-1.9 \mathrm{x} 0.9 \mathrm{~cm}$ and left ovary was not visualized. Karyotype was 45XO/46XY. A working diagnosis of Turner mosaic syndrome was made. Patient was counseled and taken up for laparoscopic bilateral gonadectomy. At laparoscopy the uterus was small in size with a broad fundus and a small gonadal tissue on the right side near round ligament (Figure 4). On the left side a streak gonad was seen. A bilateral gonadectomy and bilateral salpingectomy was done. Hysteroscopy revealed a subseptum in uterus and a subseptal resection was done. Histopathology revealed a right gonadoblastoma (Figure 5) and left streak ovary with primordial follicles.

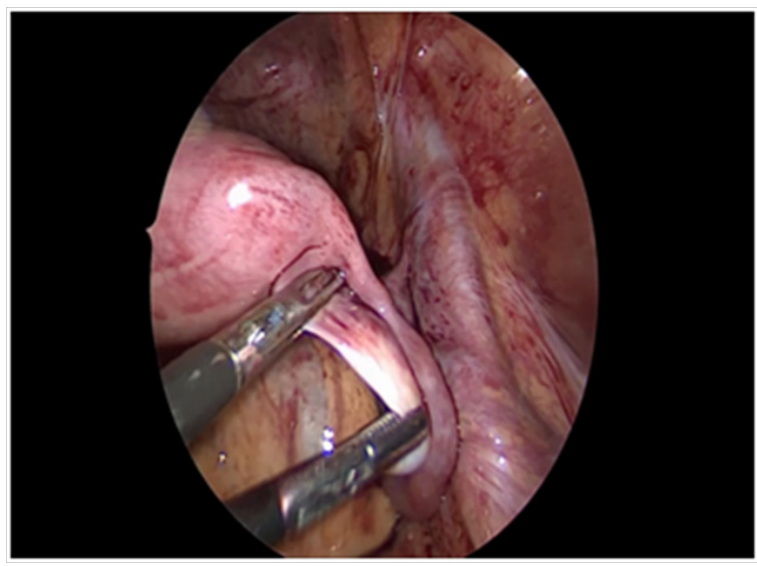

Figure 4 Right gonad with right fallopian tube.

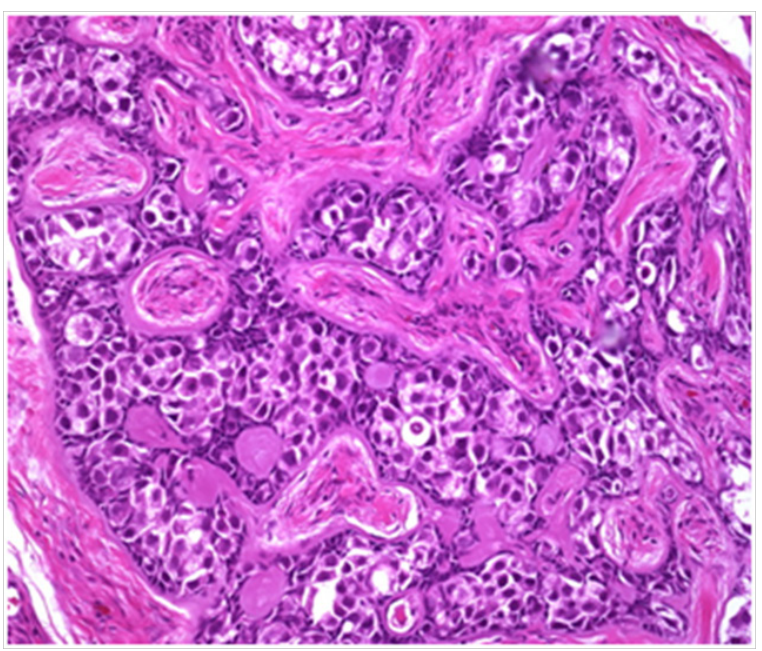

Figure 5 Right gonadoblastoma.

\section{Case 3}

A 26- year old unmarried female presented with a chief complaint of primary amenorrhea. There was no history of cyclical abdominal pain. Physical examination showed normal breast development (Tanner stage 3) with normal pubic and axillary hair (Tanner-3), normal external genitalia with a vaginal dimple. Hormone analysis showed serum FSH -9.66IU. An ultrasound scan showed absent uterus with a left ovary measuring $20 \times 16 \mathrm{~mm}$ and the right ovary measuring $22 \times 18 \mathrm{~mm}$. Karyotype was 46XX. A working diagnosis of Mullerian agenesis was made. She was taken up for diagnostic laparoscopy and neovagina creation. At laparoscopy uterus was rudimentary with bilateral normal and healthy adnexa. The space between the bladder and urethra in front and rectum and anus behind was dissected up to the pelvic peritoneum. Space was created of length 9-10 cm and width 
of 4-5 cm. An Interceed was placed on the mould and inserted into the vaginal space. Mould was removed on day 7 (Figure 6) and vaginal dilatation with estriol gel was done.

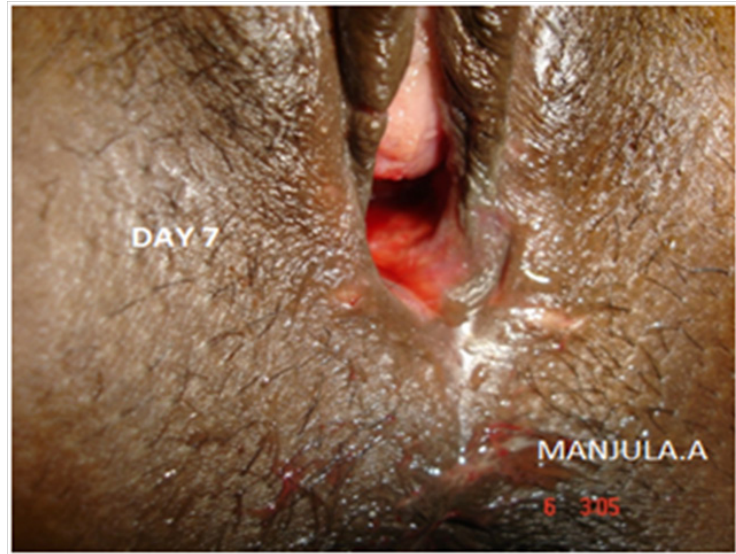

Figure 6 Neovagina after mould removal on 7th postoperative day.

\section{Discussion}

Evaluation of primary amenorrhea begins with a careful history and physical examination including the assessment of the internal and external genitalia as well as hormonal assay and karyotype. This approach will identify the most common causes of amenorrhea. ${ }^{1}$ The differential diagnosis of amenorrhea is broad and can range from genetic abnormalities to endocrine disorders and psychological, environmental, and structural anomalies. Assessment of the adolescent patient requires a sensitive, age-appropriate approach.

Primary amenorrhea with a blind or absent vagina points directly to an anomaly of the genital outflow tract. ${ }^{2}$ Prevalence of primary amenorrhea includes hypergonadotropic hypogonadism $(48.5 \%)$, hypogonadotropic hypogonadism (27.8\%), and eugonadism (23.7\%). ${ }^{3}$ The hypergonadotropic hypogonadism category includes patients with abnormal sex chromosomes (e.g. Turner syndrome), who make up $29.7 \%$ of all primary amenorrhea cases, and those with normal sex chromosomes. The latter group includes both patients who are 46, XX (15.4\%) and those who are 46,XY (3.4\%).

Meyer Rokitansky Kuster Hauser Syndrome(MRKH) is seen in approximately $10 \%$ of cases of primary amenorrhea and is the second most common cause of primary amenorrhea, behind gonadal dysgenesis. ${ }^{1}$ MRKH syndrome is caused by agenesis or partial agenesis of the müllerian duct system. It is characterized by congenital aplasia of the uterus and upper two thirds of the vagina in women showing normal development of the secondary sexual characteristics and a normal 46,XX karyotype. ${ }^{4}$ The uterus and cervix are often absent; however, $7-10 \%$ of patients have a rudimentary uterus with functional endometrium.

Androgen Insensitivity Syndrome (AIS) is a maternal X linked recessive disease in which the testes remain intra-abdominal or partially descended, and pubic hair is sparse. It has incidence of 1 in $20,400 \mathrm{XY}$ births and is present in $10 \%$ of patients with amenorrhea. It is caused by an abnormality of the androgen receptor. The gonads are testicles producing testosterone; however, testosterone has no effect because the androgen receptor is nonfunctional. This prevents masculinization of male fetus and non-development of male secondary sexual characteristics at puberty. The phenotypic appearance in patients with this condition is female with asymmetrical secondary sexual development (breast development with absent pubic hair), no visible cervix, and a short vagina. ${ }^{2}$.
Turner's syndrome (45XO karyotype) is the most common form of female gonadal dysgenesis. Clinical manifestations of Turner syndrome include a webbed neck, short stature, broad shield-like chest, anomalous auricles, and hypoestrogenemia resulting in sexual immaturity. Mosaicism occurs in approximately 25 percent of patients with Turner's syndrome. ${ }^{5}$

Female patients who have a Y chromosome have a $25 \%$ chance of developing a gonadal tumor. ${ }^{6}$ The gonads should immediately be removed to prevent the risk of malignant transformation. Hormone replacement therapy (HRT) should be offered to allow completion of puberty in a controlled fashion and should facilitate maximum bone density development. ${ }^{7}$ The risk of germ cell malignancy is relatively high in these patients and increases with age. A study of 102 phenotypic female patients with Y chromosome by Ai-Xia liu ${ }^{8}$ showed the total incidence of malignancy to be $17.6 \%{ }^{8}$. Overall risk of malignancy increases markedly after puberty and reaches $33 \%$ by the age of 50 years. ${ }^{3}$

Gonads may lie anywhere in the path of congenital descent. They are usually associated with inguinal hernia. Hernioplasty should be undertaken to prevent future hernia. Laparoscopic approach to gonadectomy is an excellent minimally invasive technique. It provides good visualization of internal genitalia, and even small gonads and mullerian structures can be removed. Postoperatively recovery is rapid with minimal discomfort to patient affording early mobilization. Gonadectomy predisposes patients to osteoporosis and other menopausal symptoms; therefore, HRT should be prescribed till the natural age of menopause to prevent accelerated ageing of body.

Vaginal agenesis involves issues of physical abnormality, body image, sexual identity, sexual and reproductive functioning \& requires long-term medical \& psychological management. Timing of intervention is important when patient attains full growth, is psychologically prepared, and is socially and/or sexually mature so that higher estrogen levels prevent stenosis and patient can perform the dilatation by herself.

Jackson and Roseblatt found in four women that with use of intercede, ${ }^{9,11}$ there were no intraoperative or postoperative complications, epithelialization of the neovagina was complete by 3-6 months with a $100 \%$ patient satisfaction and a single procedure was needed. The use of Interceed reduces the cost, operative time, and morbidity. The presence of this nonadherant layer between the mould and neovagina allows epithelialization to occur beneath the gelatinous layer thus preventing adherence. ${ }^{10}$

\section{Conclusion}

Clinicians should be aware of the presence of more than one etiology for primary amenorrhea and also of atypical presentations to avoid long-term side effects of a misdiagnosis. Management of primary amenorrhea needs a multidisciplinary team approach with timed surgical intervention to produce a optimal cosmetic and functional result and also to avoid long term psychosocial ill-effects. Chromosomal anomalies are common in patients presenting with primary amenorrhea. Early gonadectomy is advisable in XY females and Mosaics in view of increased risk of malignant transformation. Laparoscopic approach to gonadectomy is an excellent minimally invasive technique. HRT should be given to prevent osteoporosis and cardiac problems. The use of Interceed in surgical vaginoplasty is shown to give encouraging results with less operative time \& least morbidity. 


\section{Acknowledgments}

None.

\section{Conflicts of interest}

None.

\section{References}

1. The Committee of the American Society for Reproductive Medicine. Current evaluation of amenorrhea. Fertil Steril. 2008;90(5Suppl):S219S225.

2. Committee on Adolescent Health Care. Committee opinion: no. 562: müllerian agenesis: diagnosis, management, and treatment. Obstet Gynecol. 2013;121(5):1134-1137.

3. Reindollar RH, Tho SPT, McDonough PG. Delayed Puberty: an updated study of 326 patients. Transactions of the Gynecological and Obstetrical Society. 1989;8:146-162.

4. Morcel K, Camborieux L, Guerrier D. Mayer-Rokitansky-KüsterHauser (MRKH) syndrome. Orphanet J Rare Dis. 2007;2:13.

5. Simpson J, Rajkovic A. Ovarian differentiation and gonadal failure. $\mathrm{Am}$ J Med Genet. 1999;89(4):186-200.
6. Manuel M, Katayama PK, Jones HW Jr. The age of occurrence of gonadal tumors in intersex patients with a Y chromosome. Am J Obstet Gynecol. 1976;124(3):293-300.

7. Bondy CA. Care of girls and women with Turner syndrome: a guideline of the Turner Syndrome Study Group. J Clin Endocrinol. 2007;Metab92(1):10-25.

8. Liu AX, Shi HY, Cai ZJ, et al. Increased risk of gonadal malignancy and prophylactic gonadectomy: a study of 102 phenotypic female patients with Y chromosome or Y-derived sequences. Hum Reprod. 2014;29(7):1413-1419.

9. Jackson ND, Rosenblatt PL. Use of Interceed Absorbable Adhesion Barrier for Vaginoplasty. Obstet Gynecol. 1994;84(6):1048-1050.

10. Motoyama S, Laoag-Fernandez JB, Mochizuki S, et al. Vaginoplasty with Interceed absorbable adhesion barrier for complete squamous epithelialization in vaginal agenesis. Am $J$ Obstet Gynecol. 2003;188(5):1260-1264

11. Motoyama Sator. Less Invasive Surgery for Vaginoplasty Using Interceed (Oxidized Regenerated Cellulose) Absorbable Adhesion Barrier - 14 subjects. Acta Obstetrica et Gynaecologica Japonica. 2004;56(12):1353-1359. 